\title{
Investigation Report on Laboratory Confirmed Measles Case in the Hurungwe District Doro Clinic- Garangwe Area; Nziradzepatsva Village, Hurungwe District
}

\author{
Article by C.K. Chigodo ${ }^{1}$; A. Chiganga ${ }^{2}$, K. Chivende ${ }^{3}$; E .Chibika ${ }^{4}$ \\ ${ }^{1}$ National EPI Officer \\ ${ }^{2}$ District N Nursing Officer, Hurungwe District, Mashonaland West Province \\ ${ }^{3}$ District Nursing Officer, Zvimba District, Masonaland West Province \\ ${ }^{4}$ Provincial EPI Officer Mashonaland West Province \\ E-mail: collinechigodo@gmail.com
}

\begin{abstract}
This paper was carried on an Investigation in Hurungwe district, Doro catchment area following confirmation of a measles Igm measles positive case. Doro clinic is $56 \mathrm{~km}$ from the district hospital, in the western direction and the laboratory confirmed case is $20 \mathrm{~km}$ in the same direction. The community derives its income from tobacco and maize farming. Their religion is Christianity. The area has some hard-to-reach families by district and by religion.

Several cases on measles were detected and filed following the laboratory confirmation.

Based on the findings from the investigation, the following are recommend: VHW Mberikwenyanga to visit the Phiri family (vaccine objectors) to actively search for clinical measles cases and refer, Continued information giving at gatherings and homesteads by community leaders and Communitybased Health Workers, Community-based active search by VHWs, Continued information-giving to the community, Continued Active search for more cases, Continued monitoring of the index case, especially nutrition-wise, Conduct headcount of children below 1 year and 5 years, Indicate populations by village, by hard-to-reach on the REC Map, Continued mobilisation and distribution of resources and logistics, Conduct operational research, since the child received 2 valid measles dose, Urgent replacement of obsolete refrigerators and fridge tags
\end{abstract}

Keywords: Laboratory Investigation, Measles, Hurungwe District, Doro Clinic.

\section{Introduction}

Investigation was carried out in Hurungwe district, Doro catchment area following confirmation of a measles Igm measles positive case. Doro clinic is $56 \mathrm{~km}$ from the district hospital, in the western direction and the laboratory confirmed case is $20 \mathrm{~km}$ in the same direction.

The community derives its income from tobacco and maize farming. Their religion is Christianity. The area has some hard- to-reach families by district and by religion.

\section{Population breakdown for doro clinic}

Total Population 6936

Under-Ones 238

Under-Fives 1106

\section{Aim of the investigation}

To conduct a detailed investigation following a confirmed measles Igm positive case in Doro Catchment area, Hurungwe District

\section{Objectives of investigation were to}

- Carry out active search in the community of the confirmed case of measles, through the VHWs

- Conduct interviews on the Doro clinic staff

- Monitor surveillance activities at the clinic

- Assess cold chain management at Doro clinic 
DOI: 10.21522/TIJPH.2013.05.04.Art043

ISSN: $2520-3134$

\section{Highlights of activities}

Visited the clinic and assessed their knowledge and skills in routine EPI and EPI disease surveillance;

- Checked the T12 and IMNCI register and there were conducting active search as indicated by documentation of active search in the registers( see figure below)

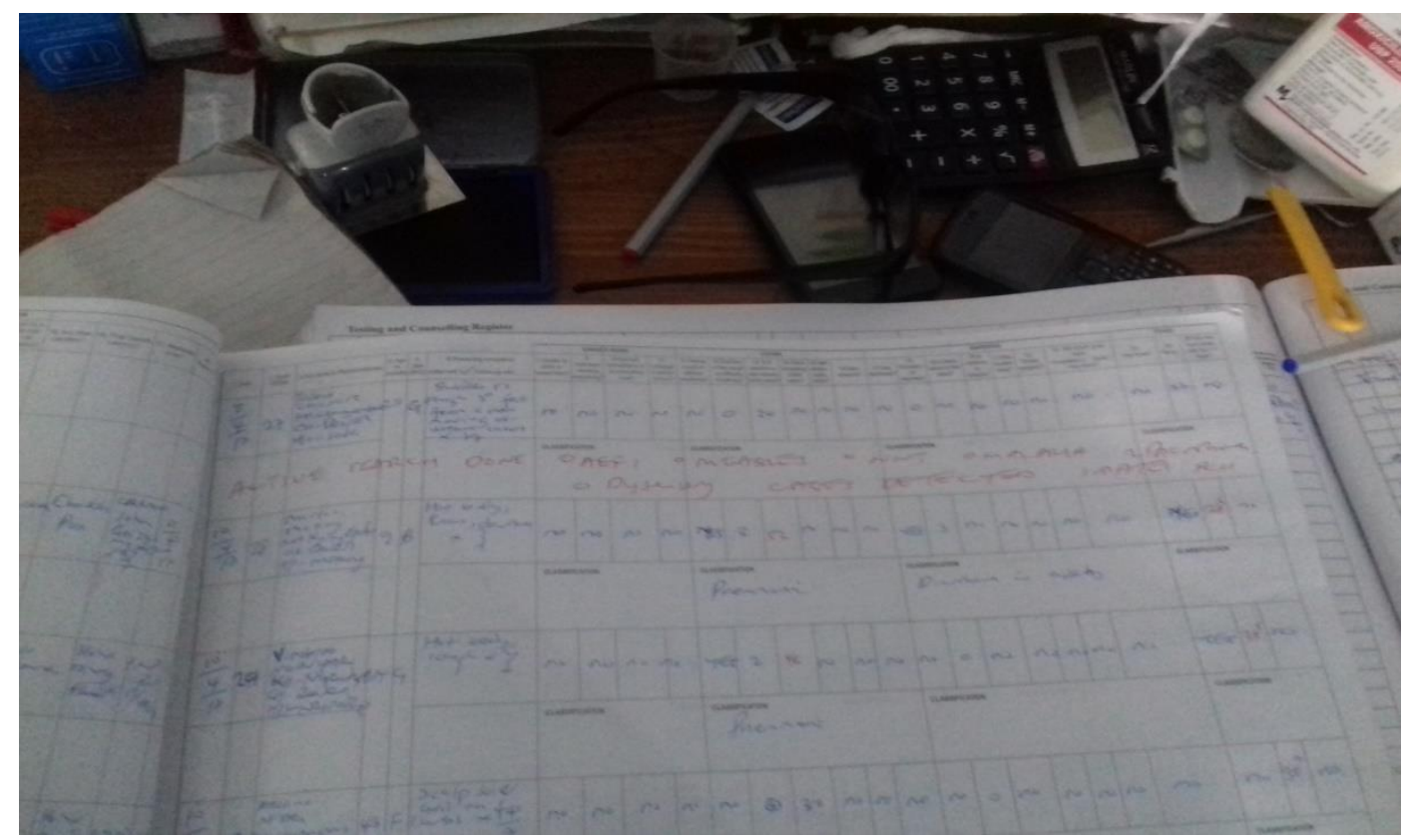

Figure 1. IMNCI register

- EPI monitoring graphs and case definitions were displayed on the walls

- Coverage for both 2016 and 2017 was above 100\% as indicated by the T6, T5 and Monitoring charts (see figure 2 below)

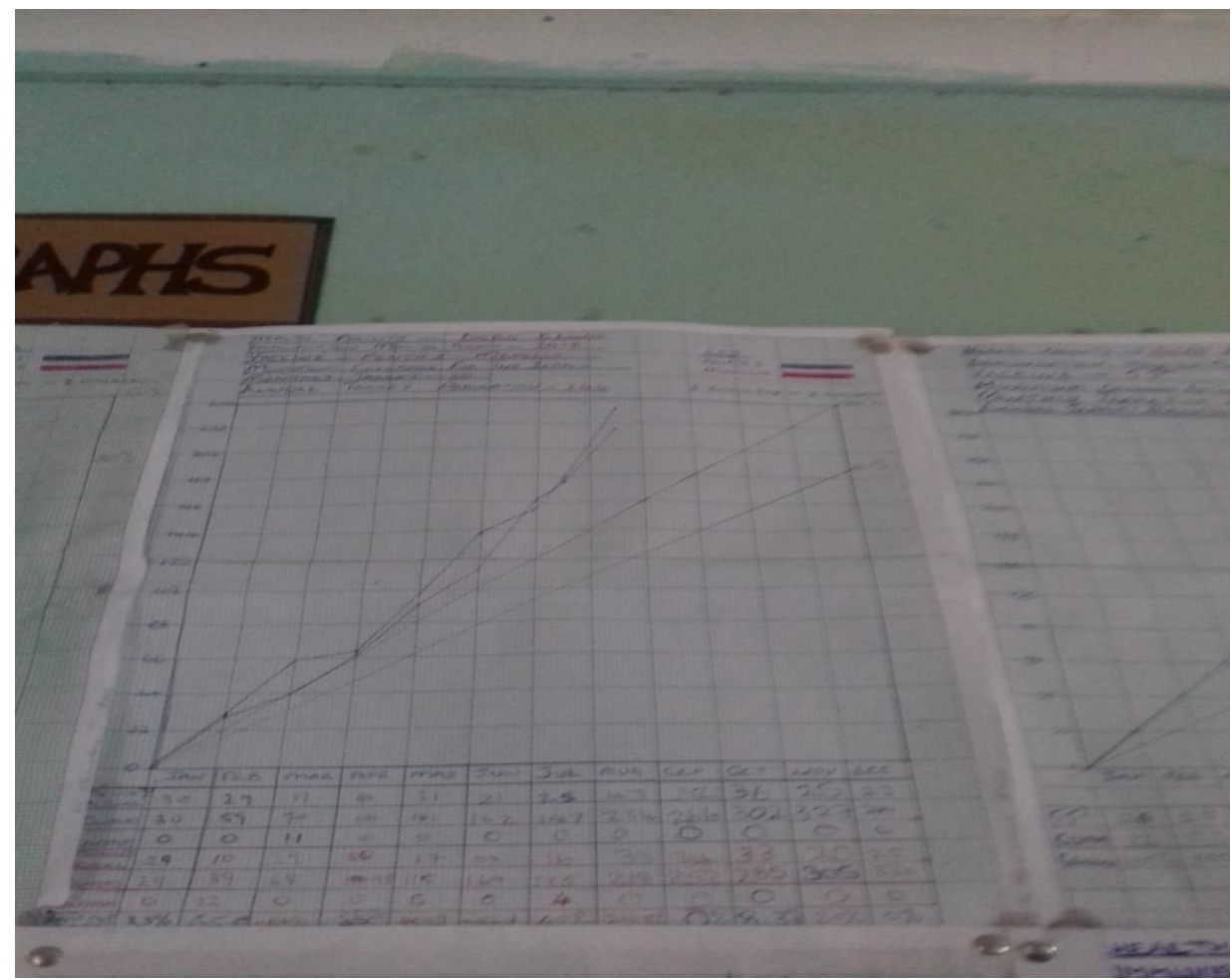

Figure 2. Vaccine monitoring graph 
- $\quad$ EPI Case definitions were displayed on the walls including the measles case definition. This helps the staff to come up with correct clinical diagnosis when assessing childhood EPI diseases. (see figure 3 below)

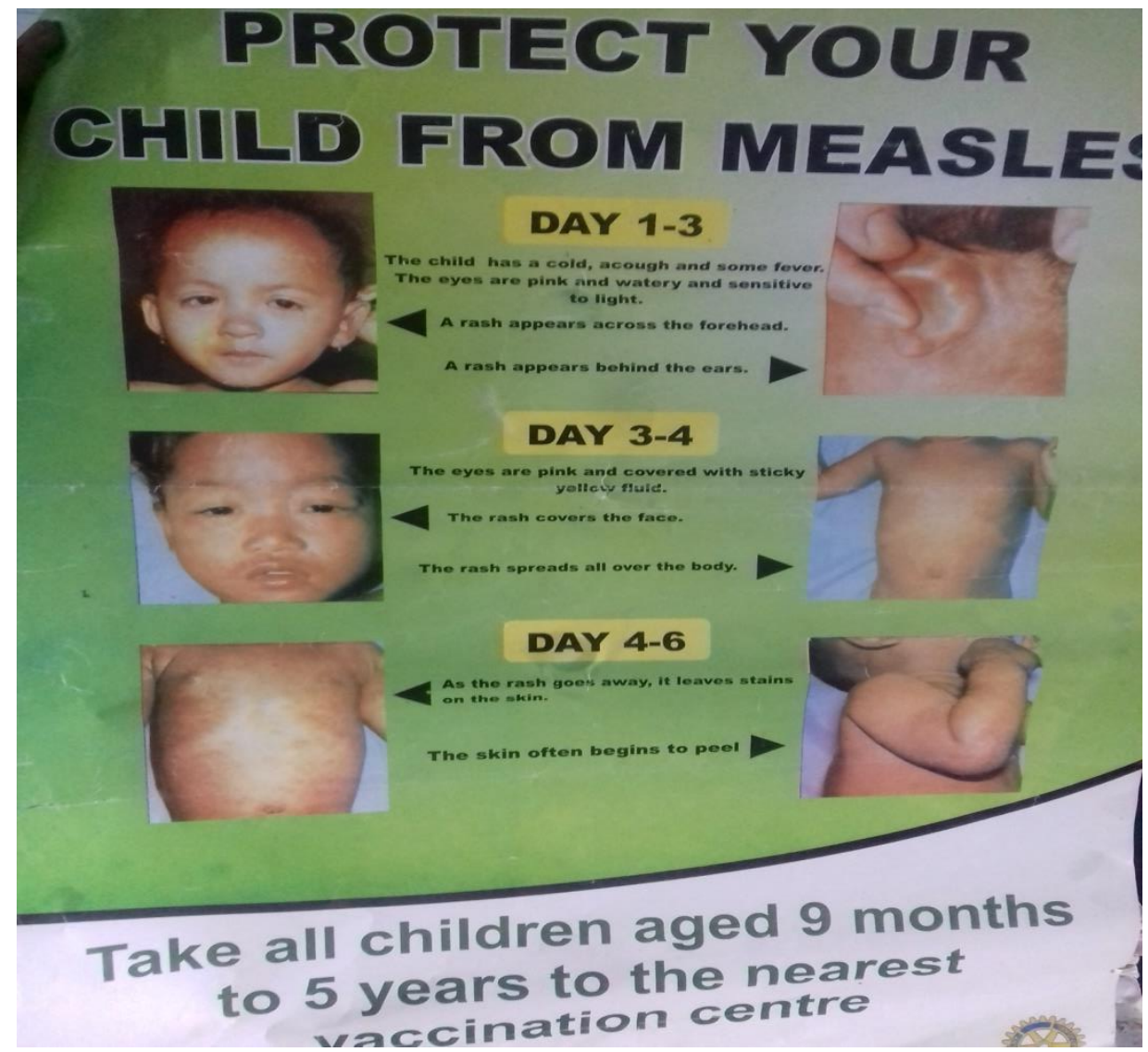

Figure 3. Measles case definition chart (WHO)

- Had adequate stocks of all antigens and had not experienced any stock outs in the past 6 months.

- Conducted interview of health staff and they were quite knowledgeable on the EPI programme, including EPI disease surveillance and EVM.

- Staff members at Doro Clinic work as a team and the same knowledge was across both members.

- Clinic staff had also carried a home visit to where the case resides

- Screened all schools around (Garangwe and Nyamupfukudza Primary Secondary Schools) and used Village Health Workers to carry out active search in the community.

- The facility identified two more cases and results were not received at the time of investigation and no more cases were identified up to time of report writing.

- Intensified social mobilization was done through dialogue with local leaders

\section{District Team}

- Supported the facility, carried out active search, visited the homestead of the case and also visited Kachingamire village where Mrs Petros and her baby had visited prior the illness.

- Sensitized people who were gathered (+- 150) celebrating Independence Day

- A total of 123 children were screened for EPI diseases. These were gathered at Karereshe business centre where the mother and child had visited.

\section{Investigation team visit to the community}

- Visited Garangwe School, which is $12 \mathrm{~km}$ from the Doro Clinic. School has an enrolment of more than 400 children. On the date of visit the teacher also confirmed that no case of measles was seen at the clinic. 
DOI: $10.21522 / \mathrm{TIJPH} .2013 .05 .04$. Art043

ISSN: $2520-3134$

- Proceeded to the homestead of the case which is in Nziradzepasi village which is 5 kilometres from the school and 15 from the clinic.

- Conducted interview of the grandparents and the mother of the case (see figure4 below)

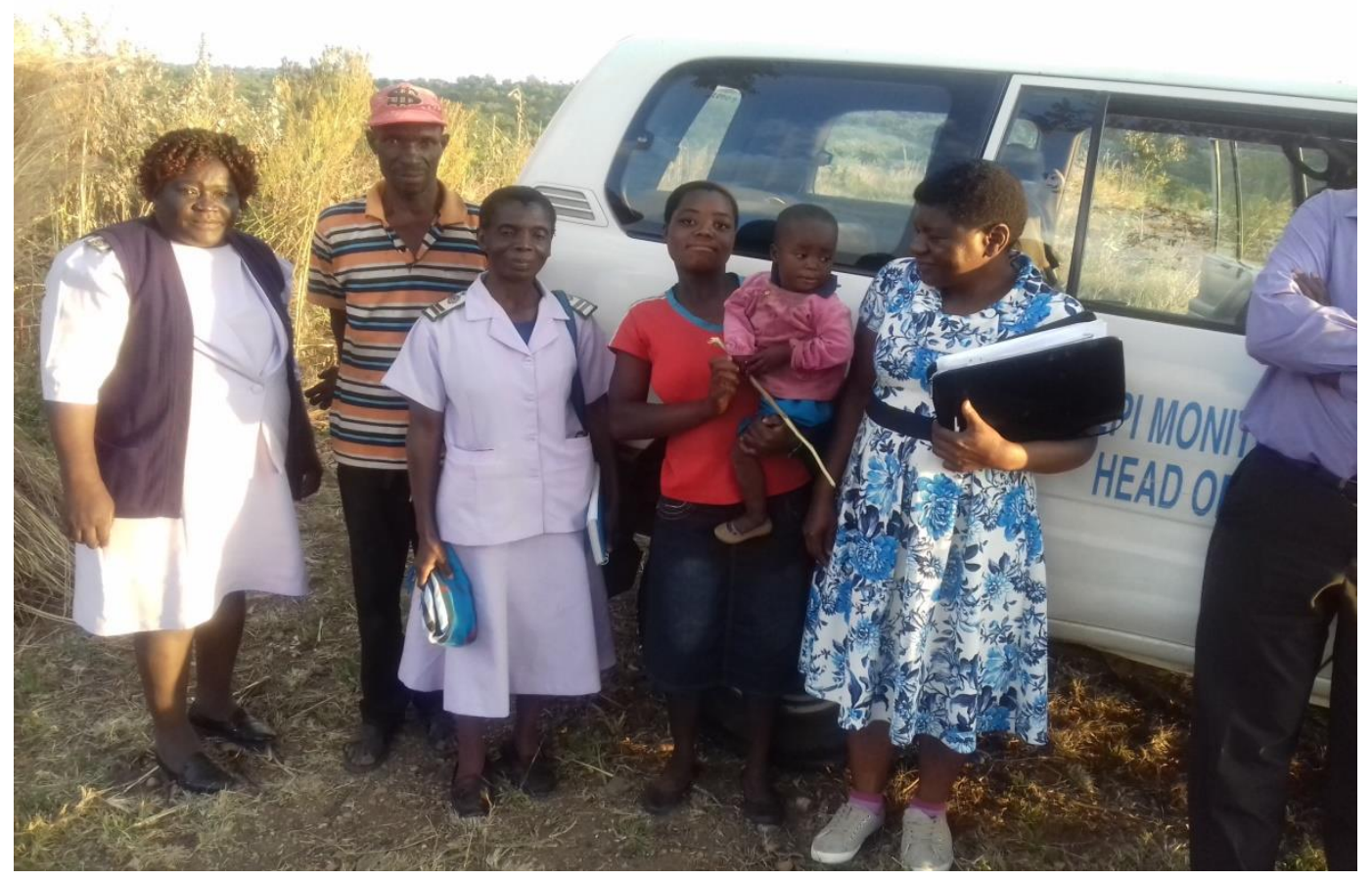

Figure 4. Interviewers and family of the case

- Both grandparents and mother could greatly articulate how the child got ill.

- They were all knowledgeable about measles community case definition

- They were so much surprised with the child having been diagnosed of measles because they believed that measles had been eliminated because of vaccinations.

- Reviewed the child health card and child was up to date with vaccinations. He received 2 valid doses of measles.

- The child is malnourished and is on plumpy nut. ( see figure 5 below) 


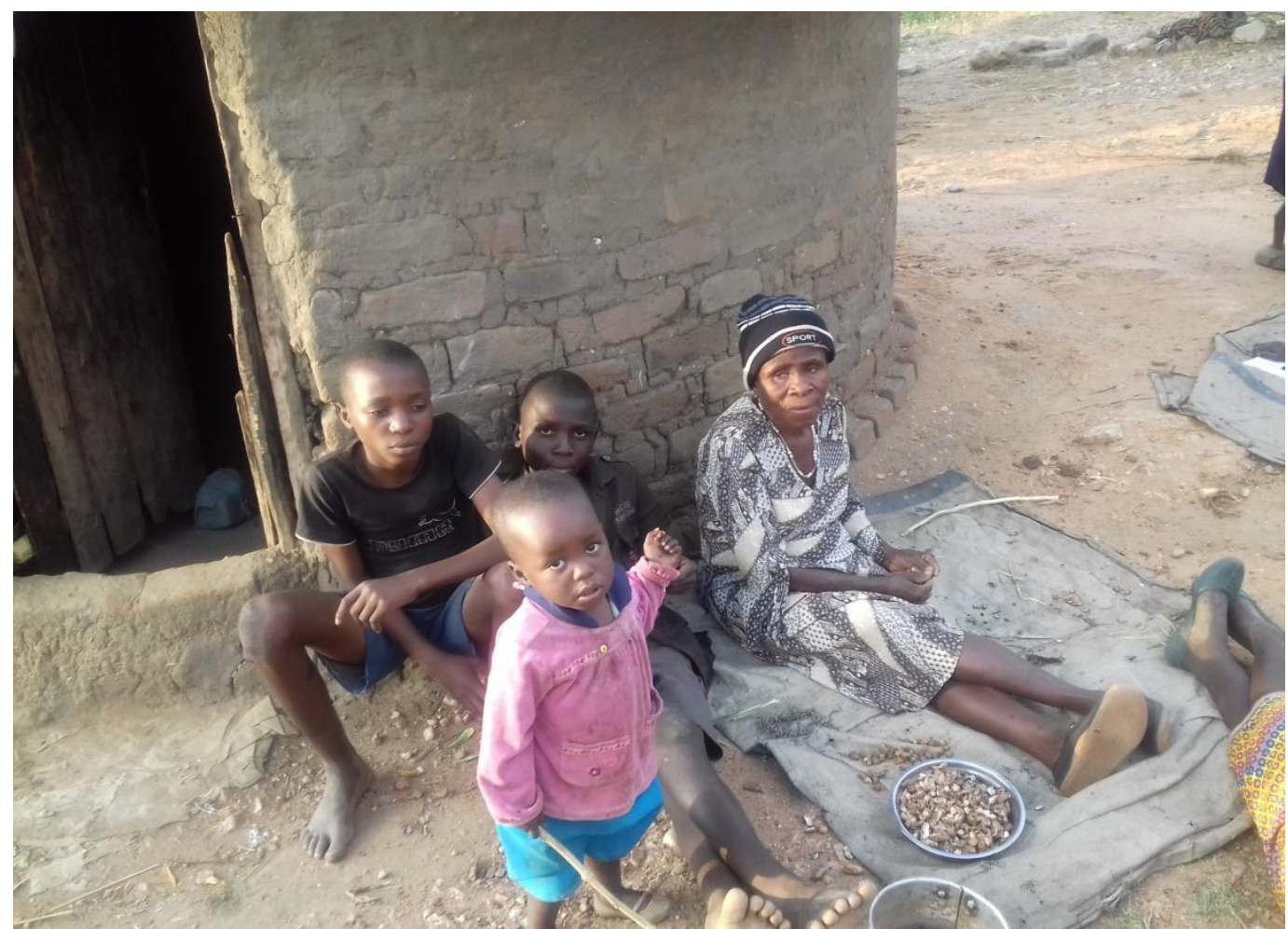

Figure 5. Measles case (Pink top)

- The grandmother referred to a homestead which is about 500metres away from their homestead as the family from the True Apostolic Sect which are objectors to vaccination.

- The team wanted to visit the homestead but were barred from doing so as they felt it would create friction with the family. However they advised that the team should give the task to the local Village Health Worker

- The team proceeded to visit the Village Health Worker -Mrs Mberikwenyanga living in the same area.

- Interviewed the Village Health Worker who said she carried out active search in the community and she did not find any suspected measles case in her catchment area.

- Passed through Village Head Bukuta who directed the team to the Village Health Worker in Kachingamire Village

- Visit to Village Health Worker Justin Chitimbe (Kachingamire and Karereshe)

- Interviewed the Village Health Worker and he was knowledgeable on measles community case definition.

- Confirmed that no cases of clinical measles were identified before and after the index case. He is continuing with community-based active search

\section{Recommendations}

a) The community

- VHW Mberikwenyanga to visit the Phiri family (vaccine objectors) to actively search for clinical measles cases and refer.

- Continued information giving at gatherings and homesteads by community leaders and Community-based Health Workers

- Community-based active search by VHWs

\section{b) The health facility staff}

- Continued information-giving to the community

- Continued Active search for more cases

- Continued monitoring of the index case, especially nutrition-wise 
DOI: $10.21522 /$ TIJPH.2013.05.04.Art043

ISSN: $2520-3134$

- Conduct headcount of children below 1 year and 5 years

- Indicate populations by village, by hard-to-reach on the REC Map.

c) The district

- Continued support to lower level facilities

- Continued mobilisation and distribution of resources and logistics

\section{d) The national level}

- Conduct operational research, since the child received 2 valid measles doses

- Urgent replacement of obsolete refrigerators and fridge tags

\section{References}

[1]. Atrasheuskaya AV, Kulak MV, Neverov AA, Rubin S, Ignatyev GM. Measles cases in highly vaccinated population of Novosibirsk, Russia, 2000-2005. Vaccine. 2008 Apr 16; 26(17):2111-8.

[2]. Campbell C, Levin S, Humphreys P, Walop W, Brannan R. Subacute sclerosing panencephalitis: results of the Canadian Paediatric Surveillance Program and review of the literature. BMC Pediatr. 2005 Dec 15; 5:47.

[3]. Davidkin I, Jokinen S, Broman M, Leinikki P, Peltola H. Persistence of measles, mumps, and rubella antibodies in an MMR-vaccinated cohort: a 20-year follow-up. J Infect Dis. 2008 Apr 1; 197(7):950-6.

[4]. Dine MS, Hutchins SS, Thomas A, Williams I, Bellini WJ, Redd SC. Persistence of vaccineinduced antibody to measles 26-33 years after vaccination. J Infect Dis. 2004 May 1; 189 Suppl 1:S123-30.

[5]. Enquselassie F, Ayele W, Dejene A, Messele T, Abebe A, Cutts FT, Nokes DJ. Seroepidemiology of measles in Addis Ababa, Ethiopia: implications for control through vaccination. Epidemiol Infect. 2003 Jun; 130 (3):507-19.

[6]. Hirose M, Hidaka Y, Miyazaki C, Ueda K, Yoshikawa H. Five cases of measles secondary vaccine failure with confirmed seroconversion after live measles vaccination. Scand J Infect Dis. 1997; 29 (2):187-90.

[7]. Nandy R, Handzel T, Zaneidou M, Biey J, Coddy RZ, Perry R, Strebel P, Cairns L. Casefatality rate during a measles outbreak in eastern Niger in 2003. Clin Infect Dis. 2006 Feb 1; 42 (3):322-8.

[8]. Perry RT, Halsey NA. The clinical significance of measles: a review. J Infect Dis. 2004 May 1; 189 Suppl 1:S4-16.

[9]. Samb B, Aaby P, Whittle HC, Seck AM, Rahman S, Bennett J, Markowitz L, Simondon F. Serologic status and measles attack rates among vaccinated and unvaccinated children in rural Senegal. Pediatr Infect Dis J. 1995 Mar; 14 (3):203-9.

[10].WHO: Progress in global measles control and mortality reduction, 2000-2007. Wkly Epidemiol Rec 2008; 83, 441-448.

[11].Wolfson LJ, Grais RF, Luquero FJ, Birmingham ME, Strebel PM. Estimates of measles case fatality ratios: a comprehensive review of community-based studies. Int J Epidemiol. 2009 Feb; 38 (1):192-205. 